\title{
Instrumentos para avaliação formativa da alfabetização: princípios conceituais e metodológicos
}

\author{
Renata Sperrhake
}

Luciana Piccoli

\section{Resumo}

A avaliação da aprendizagem na alfabetização é discutida com base na análise de instrumentos utilizados em experiências escolares com turmas de primeiro ano do ensino fundamental. Inicialmente, os pressupostos da avaliação formativa são utilizados para contextualizar o processo avaliativo. Em seguida, fundamentados nas perspectivas psicogenética e fonológica - paradigmas que explicam a aprendizagem do sistema alfabético-ortográfico pela criança - são apresentados princípios conceituais e metodológicos para avaliar os níveis de conceitualização da escrita, o conhecimento das letras, consciência silábica, consciência grafofonêmica e o conhecimento das relações fonema-grafema ou consciência fonografêmica. Conclui-se que o olhar interpretativo docente, com base nas diferentes teorias que explicam o processo de aprendizagem inicial da leitura e da escrita, é o que vai direcionar a avaliação das aprendizagens dos alunos. Essa constatação evidencia a importância do conhecimento específico da alfabetizadora para o acompanhamento das aprendizagens das crianças e para a organização de situações de ensino que favoreçam o avanço de seus alunos considerando as diferentes possibilidades de intervenção.

Palavras-chave: alfabetização; avaliação da aprendizagem; instrumentos de avaliação. 


\section{Abstract \\ Assessment of initial reading and writing learning: conceptual and methodological principles}

This article discusses the assessment of initial reading and writing learning by analyzing instruments used in school experiences in first-year classes of elementary school. There is a contextualization of the evaluation process through the assumptions of formative evaluation. Subsequently, based on the phonological and psychogenetic perspectives - which are paradigms that explain the children's learning of the alphabetical-orthographic system -, conceptual and methodological principles are presented and discussed to evaluate the conceptualization of writing, knowledge of letters, syllabic awareness, graphophonemic awareness and knowledge of phonemegrapheme relations or, as it may also be called, phonographic awareness. Finally, it is concluded that the teacher's interpretation is what will guide the assessment of students' learning, based on the different theories that explain the initial learning process of reading and writing. This finding shows the importance of the specific knowledge of the teacher of initial reading and writing instruction for monitoring children's learning and organizing teaching situations that favor the betterment of students considering the different possibilities of intervention.

Keywords: evaluation instruments; initial reading and writing instruction; learning assessment.

\section{Resumen \\ Instrumentos para la evaluación formativa de la alfabetización: principios conceptuales y metodológicos}

La evaluación del aprendizaje en la alfabetización se discute a partir del análisis de instrumentos utilizados en experiencias escolares con las clases de primer año de la escuela primaria. Inicialmente, los supuestos de la evaluación formativa se utilizan para contextualizar el proceso de evaluación. Luego, fundamentados en las perspectivas psicogenética y fonológica -paradigmas que explican el aprendizaje del sistema alfabéticoortográfico por parte del niño-se presentan principios conceptuales y metodológicos para evaluar los niveles de conceptualización de la escritura, el conocimiento de las letras, conciencia silábica, conciencia grafofonémica y el conocimiento de las relaciones fonemagrafema o conciencia fonografémica. Se concluye que la mirada interpretativa docente, basada en las diferentes teorías que explican el proceso de aprendizaje inicial de lectura y escritura, es lo que guiará la evaluación del aprendizaje de los estudiantes. Este hallazgo muestra la importancia del conocimiento específico del alfabetizador para monitorear el aprendizaje de los niños y organizar situaciones de enseñanza que favorezcan el progreso de sus alumnos considerando las diferentes posibilidades de intervención.

Palabras clave: alfabetización; evaluación del aprendizaje; instrumentos de evaluación. 


\section{Introdução}

A questão que guia a escrita deste artigo é a seguinte: quais são os subsídios teóricos e metodológicos necessários para que as alfabetizadoras ${ }^{1}$ possam avaliar a aprendizagem inicial da leitura e da escrita de seus alunos?

Buscando responder a tal questionamento, valemo-nos de uma análise qualitativa de instrumentos de avaliação utilizados em turmas de primeiro ano do ensino fundamental, de escolas das redes públicas de ensino estadual do Rio Grande do Sul e do município de Porto Alegre (RS), no período de 2015 a 2019. Esses instrumentos provêm de um acervo de recursos didáticos ${ }^{2}$ compilado ao longo de anos de atuação nas orientações de estágios de docência dos anos iniciais do ensino fundamental do curso de Pedagogia da Universidade Federal do Rio Grande do Sul (UFRGS).

Compõem a empiria analisada neste trabalho:

1) instrumentos avaliativos planejados e criados pelas professoras alfabetizadoras; e

2) planejamentos semanais e planos diários com as situações avaliativas descritas.

Esses instrumentos de avaliação, que integram a documentação produzida, ${ }^{3}$ serão examinados considerando duas unidades de análise: os conhecimentos linguísticos em foco e a forma de produção das avaliações.

\section{Avaliação formativa na alfabetização}

Avaliar a aprendizagem na alfabetização é uma tarefa em torno da qual giram diferentes complexidades: o que, como e com que instrumentos avaliar e como registrar essa avaliação? A avaliação tem implicações fundamentais nos processos de ensino e aprendizagem quando o consideramos parte efetiva do trabalho pedagógico e, portanto, "o professor não deve se eximir de sua responsabilidade do ato de avaliar as aprendizagens de seus estudantes [...]" (Fernandes; Freitas, 2007, p. 17).

Convém destacar a qual concepção de avaliação nos vinculamos e, para tanto, começamos apontando que nos distanciamos daquela que se limita à valoração dos resultados obtidos pelos alunos. Não que esses resultados não sejam necessários, porém eles não abarcam a totalidade da prática avaliativa da maneira como queremos

\footnotetext{
${ }^{1}$ Utiliza-se o termo "professoras alfabetizadoras" ao longo do artigo pois a grande maioria das pessoas que trabalham em turmas de alfabetização são do gênero feminino.

2 Tal acervo está registrado como Projeto de Extensão "Didacoteca: acervo de recursos didáticos" e está disponível para empréstimo e consulta na Faculdade de Educação (Faced) da UFRGS e nas redes sociais.

${ }^{3}$ Agradecemos às professoras Andressa Borges e Silva, Francini Rosa Fagundes, Laura Bagatini de Almeida, Laura Dexheimer Trein, Mariele Grösz e Marian Neves Dante pela generosidade na disponibilização dos materiais analisados neste artigo.
} 
defendê-la neste texto. Além disso, entendemos que a avaliação não está localizada apenas em momentos isolados ou definidos do processo didático. Queremos argumentar em favor de uma atitude avaliativa docente em relação às aprendizagens dos alunos, e ao próprio trabalho pedagógico, que esteja em constante funcionamento. E, por fim, compreendemos que a avaliação não deve ser tomada como uma exigência burocrática que ocorre em intervalos de tempo preestabelecidos. Desse modo, fica claro que não trataremos de avaliação da alfabetização apenas no sentido de classificar e hierarquizar as aprendizagens dos estudantes. Todo nosso investimento, neste texto, é fornecer subsídios teóricos e metodológicos para que as alfabetizadoras possam analisar a aprendizagem inicial da leitura e da escrita de seus alunos numa perspectiva de avaliação formativa, que, para Zabala (1998, p. 200), é

[...] aquela que tem como propósito a modificação e a melhora contínua do aluno que se avalia; quer dizer, que entende que a finalidade da avaliação é ser um instrumento educativo que informa e faz uma valoração do processo de aprendizagem seguido pelo aluno, com o objetivo de lhe oportunizar, em todo momento, as propostas educacionais mais adequadas.

Já Perrenoud (1999, p. 103 - grifos do autor) define como "[...] formativa toda a avaliação que ajuda o aluno a aprender e a se desenvolver, ou melhor, que participa da regulação das aprendizagens e do desenvolvimento no sentido de um projeto educativo".

Das duas definições citadas, podemos destacar alguns aspectos. O primeiro deles aborda a avaliação como um instrumento que pretende auxiliar o aluno no avanço de suas aprendizagens; o segundo se refere ao papel da professora nesse processo, que seria de acompanhamento intencional, com o objetivo de oferecer à turma e a cada aluno melhores oportunidades de ensino; e o terceiro focaliza justamente a perspectiva não homogeneizante dessa concepção de avaliação, visto que cada criança segue um caminho particular rumo aos objetivos de aprendizagem traçados.

Uma avaliação formativa visa à "regulação dos processos de aprendizagem" (Perrenoud, 1999, p. 104); por "regulação" podemos entender acompanhamento e intervenção, pois cabe à professora realizar observações atentas que lhe permitam orientar seus alunos em direção aos conhecimentos em foco, os quais, no caso deste texto, são aqueles que lhes possibilitam aprender a ler e a escrever. Salientamos que não são apenas as observações que norteiam a ação docente em sala. São fundamentais a produção e a utilização de instrumentos de avaliação e de regulação das aprendizagens, que serão nosso foco de análise mais adiante. Para que esse processo de regulação aconteça, é essencial que se proceda a uma avaliação diagnóstica que, de acordo com Zabala (1998), integra a avaliação formativa. Esse diagnóstico das aprendizagens permite que a professora identifique o que os seus alunos já sabem e delimite o "ponto de partida" por meio do qual cada aluno irá traçar seu percurso de aprendizagem.

Outro ponto-chave dessa concepção de avaliação é que ela considera que entre os alunos existem diferenças (de várias ordens) e, por essa razão, como uma forma de encará-las, as professoras precisam dispor de mecanismos de 
acompanhamento e regulação das aprendizagens de cada aluno, individualmente, e do grupo de alunos, como um coletivo. Essa ideia nos parece pertinente ante as demandas contemporâneas que temos visto nas escolas, em que a heterogeneidade dos discentes em relação à aprendizagem da leitura e da escrita é a regra em turmas de alfabetização dos primeiro, segundo e terceiro anos do ensino fundamental. Nesse sentido, julgamos apropriada uma concepção de avaliação que nos forneça subsídios para pensar e agir em função dessa heterogeneidade das turmas de alfabetização.

Uma questão que se coloca com bastante frequência quando se discute avaliação, de um modo geral, e avaliação da alfabetização, de um modo específico, diz respeito aos instrumentos empregados para realizar essa avaliação e as formas de registro das aprendizagens. Entendemos que esses instrumentos podem ser utilizados para tornar visível o percurso educativo "[...] por meio de uma documentação atenta dos dados relativos às atividades, para os quais se pode valer tanto de instrumentos de tipo verbal, gráfico e documentativo quanto de tecnologias audiovisuais mais difundidas nas escolas" (Rinaldi, 2014, p. 80).

Convém destacar, ainda, que a avaliação formativa funciona em conjunto com uma perspectiva didática em que a professora deve ser levada

[...] a observar mais metodicamente os alunos, a compreender melhor seus funcionamentos de modo a ajustar de maneira mais sistemática e individualizada suas intervenções pedagógicas e as situações didáticas que propõe, tudo isso na perspectiva de otimizar as aprendizagens. (Perrenoud, 1999, p. 89).

Ou seja, a atitude avaliativa assumida pela docente na sua sala de aula, apoiada na avaliação formativa, implica uma análise do próprio processo didático e de ensino, pois, ao buscar regular os processos de aprendizagem discente, também se estará pensando e repensando as estratégias de ensino e de intervenção selecionadas para a turma e/ou para cada aluno. Nesse sentido, os instrumentos de avaliação precisam estar alinhados à organização do trabalho pedagógico mais amplo, isto é, a avaliação não se separa do ensino, ao contrário, ela não é "[...] senão uma peça de um dispositivo mais vasto" (Perrenoud, 1999, p. 108), devendo, portanto, ser pensada no escopo de uma didática. A avaliação em sala de aula apresenta muitos propósitos e, relacionada à aprendizagem, objetiva que a professora tenha informações úteis à tomada de decisão e capazes de orientar suas ações de modo a promover propostas didáticas adequadas aos seus alunos.

\section{Avaliação da faceta linguística da alfabetização}

Distantes da intenção de abordar a avaliação da alfabetização em suas diferentes facetas, ao realizar nosso recorte nos apoiamos em Magda Soares (2016) para circunscrever a alfabetização à sua faceta linguística, ou seja, à dimensão do processo de aprendizagem inicial da língua escrita. O objeto de conhecimento em questão é, portanto, essencialmente linguístico: o sistema alfabético-ortográfico de escrita. 
Segundo a autora, há dois principais paradigmas que explicam a aprendizagem do sistema alfabético-ortográfico pela criança: a perspectiva psicogenética e a perspectiva fonológica. É o estudo seminal de Ferreiro e Teberosky (1985) acerca da conceitualização da escrita pela criança que representa a perspectiva psicogenética. As autoras definem níveis de desenvolvimento - que são citados ao longo deste texto -, considerando os processos cognitivos do aprendiz na progressiva aproximação rumo à compreensão do sistema de escrita, entendido como um sistema de representação.

A perspectiva fonológica, representada por Linnea Ehri, trata o sistema de escrita como um sistema notacional, para o qual a compreensão/abstração da forma como se realizam as relações letra-som é fundamental. Assim, o aprendiz precisa desenvolver diferentes habilidades de consciência fonológica e, sobretudo, perceber as relações entre as letras e os sons de modo a ler e escrever.

Tendo em vista esses paradigmas, apresentaremos princípios conceituais e metodológicos para avaliar leitura e escrita de palavras e pequenos textos considerando os seguintes conhecimentos específicos da alfabetização, os quais Soares (2016) coloca em relação: níveis de conceitualização da escrita, conhecimento das letras, consciência silábica, consciência grafofonêmica e conhecimento das relações fonema-grafema ou consciência fonografêmica (Figura 1). Com esses conhecimentos específicos, iremos descrever e analisar instrumentos avaliativos utilizados em experiências escolares, salientando os conhecimentos observados a partir daquilo que é predominante, pois sabemos que um mesmo instrumento pode avaliar habilidades distintas.

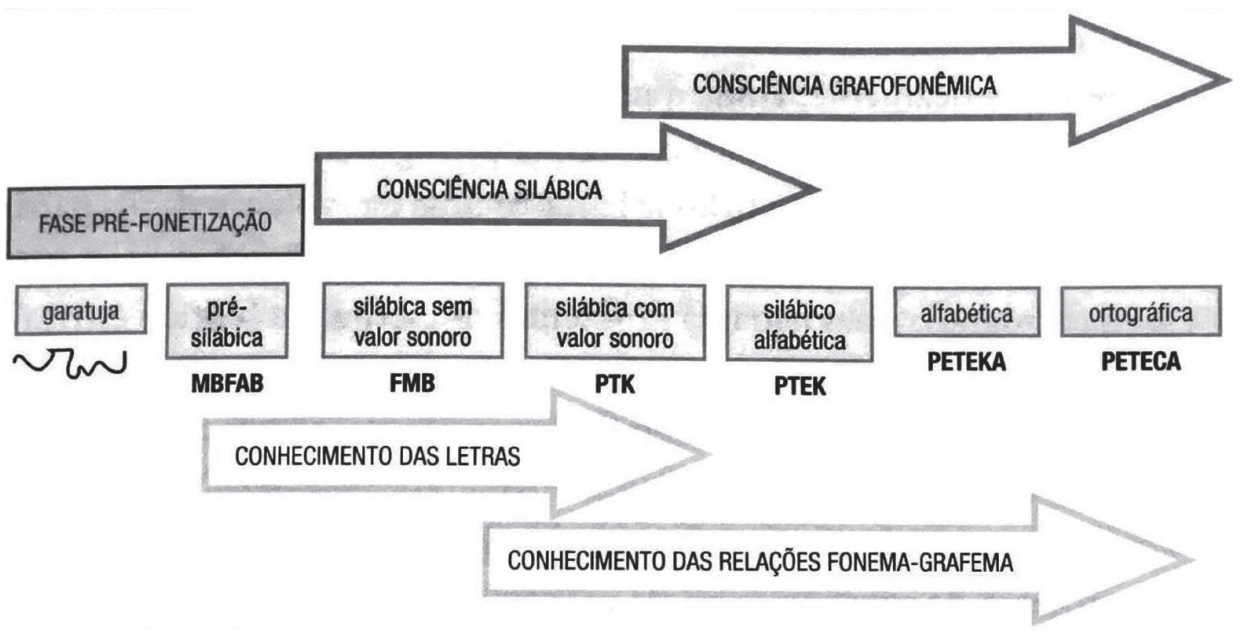

Figura 1 - Princípios conceituais e metodológicos para avaliar leitura e escrita de palavras e pequenos textos

Fonte: Soares (2016, p. 235). 


\section{Instrumentos para avaliação da alfabetização}

Nesta seção, apresentamos e analisamos diferentes instrumentos para avaliação da aprendizagem inicial da leitura e da escrita, evidenciando a faceta linguística da alfabetização, que consistem em folhas estruturadas e jogos produzidos ou adaptados pelas professoras. Além disso, exibiremos trechos dos planejamentos escritos nos quais há a descrição de como tais instrumentos foram utilizados em sala de aula e quais conhecimentos linguísticos estavam sendo avaliados.

Soares (2016) ressalta que o conhecimento das letras é componente fundamental para a compreensão do princípio alfabético, já que são elas que tornam os fonemas "visíveis" na escrita. No processo de conhecimento das letras, as crianças as tomam, primeiramente, como formas visuais que elas aprendem a nomear, assim como aprendem a nomear outros objetos do mundo. Após esse período, as crianças passam a "reconhecer e tentar escrever letras" (Soares, 2016, p. 210), porém, nesse momento, estas ainda são como objetos, ou seja, não exercem uma função simbólica. Nessa segunda etapa, a criança ainda não distingue letras de números. A terceira e última etapa é, justamente, quando a criança passa a compreender que as letras que utilizamos na escrita têm uma função representativa dos sons da fala.

No excerto de planejamento mostrado na Figura 2, podemos ver a avaliação do conhecimento das letras sendo realizada, no início do ano letivo, de três maneiras diferentes: após um momento de escrita inventada, individualmente; depois em um momento lúdico, coletivamente, mediante a brincadeira "O limão entrou na roda"; e, finalmente, de novo de forma individual, em folha de sistematização.

A avaliação do conhecimento das letras, como afirma Soares (2016), além de favorecer o desenvolvimento da consciência grafofonêmica, uma vez que a identificação de fonemas é facilitada quando o aluno sabe os nomes das letras, também é fundamental para a compreensão do funcionamento do sistema alfabético de escrita e para a progressão nos níveis psicogenéticos.

Para que a criança avance no entendimento do sistema de escrita, também é necessário que ela tenha consciência da segmentação da palavra em sílabas, o que a introduzirá no período de fonetização da escrita. A avaliação da consciência silábica pode se dar nos níveis da oralidade e da escrita, ou seja, a criança pode ser capaz de segmentar oralmente as palavras em unidades menores, as sílabas, e de representar essas unidades com caracteres escritos, geralmente letras. No que se refere à avaliação da escrita, ainda apresentaremos alguns instrumentos neste texto, portanto, no momento, focalizaremos aqueles destinados à avaliação da consciência silábica como habilidade de segmentação oral da palavra em sílabas. 
Apresentarei uma cartela com as letras do alfabeto, pedindo que cada criança me mostre quais letras conhece, dizendo seus nomes.

Depois, pedirei que me acompanhem até o saguão, sentando-se em um círculo. Explicarei que faremos um jogo, mostrando-lhes um saquinho com diferentes letras e números de E.V.A. Direi então: "Dentro deste saquinho, nós temos letras e números. Quem conhece a música 'O limão entrou na roda'? Hoje nós vamos cantar ela um pouquinho diferente: 'O saquinho entrou na roda, ele passa de mão em mão. Ele vai, ele vem, ele ainda não chegou. Ele vai, ele vem, ele acaba de chegar!'. Aquele que ficar com o saquinho, vai ter que tirar algo de dentro e vai nos dizer se é uma letra ou um número e que letra ou número ele é. Se for uma letra, vai tentar também dizer uma palavra que começa com essa letra. Caso não saiba, a gente ajuda, mas nós temos que deixar o colega tentar sozinho antes!".

Finalizado o nosso jogo, pedirei que todas as crianças retomem para a sala. Distribuirei para cada aluno uma folha e um kit, como no exemplo abaixo, com letras e números já recortados e embaralhados. Realizaremos uma sistematização do jogo realizado, bem como o registro da testagem de identificação de letras e números. Encaminharei então: "O que vocês ganharam neste material? O que está escrito deste lado da folha? E deste? Agora, como nós fizemos durante o jogo, vocês vão separar as letras e os números. As letras vão ser coladas do lado esquerdo, onde diz LETRAS, essa palavra que começa com L (fazendo o desenho da folha no quadro). E os números vão ser colados do lado direito, onde diz NÚMEROS, essa palavra que começa com $\mathrm{N}$. Nessa atividade, como na atividade que fizemos ontem, queremos ver o que vocês já sabem, então tentem fazer ela sozinhos, sem pedir ajuda para os colegas e para a profe.".
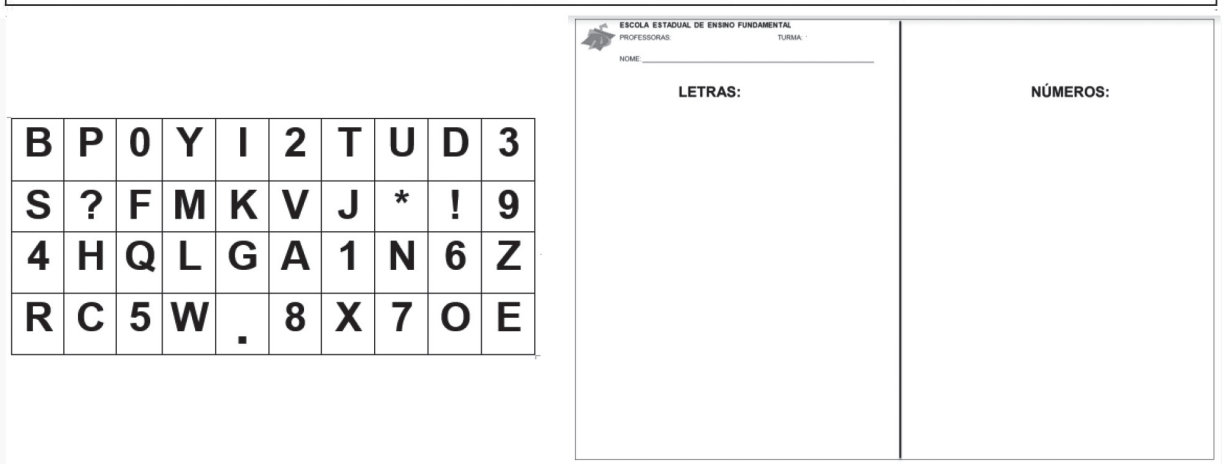

Figura 2 - Excerto de planejamento e instrumentos para avaliar o conhecimento de letras e números

Fonte: Laura Dexheimer Trein, jogo doado à Didacoteca. Imagem: Google Imagens.

Morais (2019) argumenta que algumas habilidades de consciência fonológica já podem ser desenvolvidas e acompanhadas pela professora durante o final da educação infantil. Como estamos analisando instrumentos destinados a turmas de primeiro ano do ensino fundamental, faz-se pertinente a avaliação das habilidades citadas por Morais (2019, p. 216), entre as quais selecionamos três: 1) dizer palavras separando suas sílabas; 2) contar quantos "pedaços" uma palavra tem; 3) identificar qual é a maior entre duas palavras escutadas. Essas habilidades foram avaliadas pelas professoras utilizando dois diferentes instrumentos: jogos e, posteriormente, folhas estruturadas.

Um dos jogos usados para avaliação dessas habilidades de consciência silábica foi o "Batalha de Palavras" (Brandão et al., 2008). Nesse jogo, que compõe o material didático disponibilizado às escolas públicas participantes do Pacto Nacional pela Alfabetização na Idade Certa (Pnaic), as crianças precisam refletir sobre os segmentos orais - sílabas - de nomes de imagens, de modo a identificar qual palavra é a maior (Figura 3). 


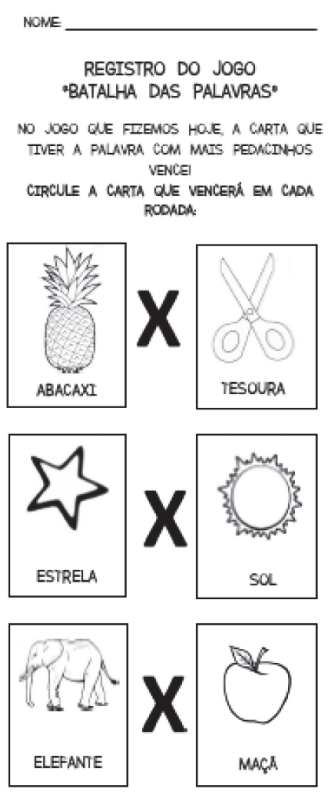

Figura 3 - Registro do jogo Batalha das Palavras para avaliar consciência silábica Fonte: Laura Dexheimer Trein, jogo doado à Didacoteca. Imagens: Google Imagens.

Corrida silábica: monta-se um "tabuleiro gigante" na sala, com duas trilhas diferentes - uma para cada equipe. A primeira equipe a jogar retira uma figura de um baralho, podendo avançar na trilha a quantidade de casas correspondente ao número de sílabas da palavra que retirou.

Figura 4 - Descrição do jogo Corrida Silábica

Fonte: Laura Dexheimer Trein, jogo doado à Didacoteca. Imagens: Google Imagens.

O objetivo do jogo Quantificação silábica é contar o número de sílabas de uma palavra. A criança deverá atribuir uma ficha para cada sílaba e identificar qual número representa a quantidade total.

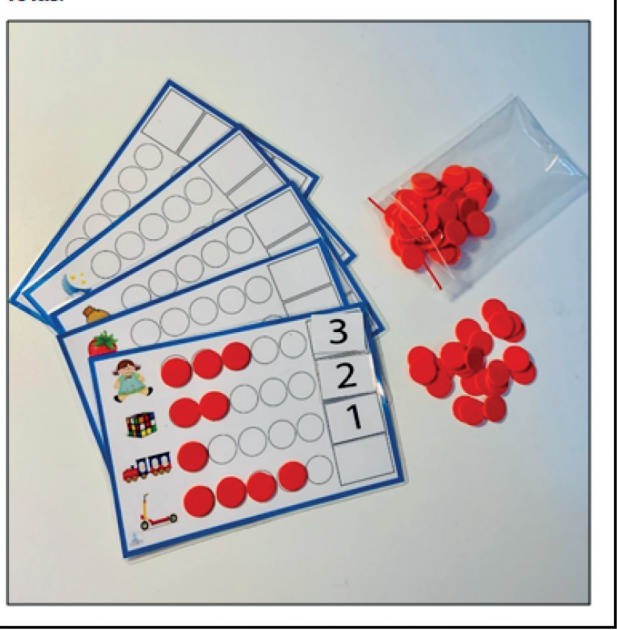

Figura 5 - Descrição e imagem do jogo Quantificação Silábica

Fonte: Laura Bagatini de Almeida e Andressa Borges e Silva - Jogo do Acervo da Illuminare - Ateliê Didático, doado à Didacoteca. 
Avaliação diagnóstica de consciência silábica: reunirei os alunos em roda para realizar a atividade de avaliação de consciência silábica. Antes de começarmos, faremos algumas rodadas coletivamente com objetos da sala (mesa, estojo, quadro). Dentro de um saquinho colocarei imagens diversas, tanto que se referem a palavras monossílabas, dissílabas e polissílabas (conforme exemplo a seguir). Cada aluno pegará uma imagem, mostrará para o grupo para que todos possam ver e terá que dizer quantos pedacinhos tem a palavra ou quantas vezes abrimos a boca para falar a palavra que foi pega por ele. Durante a atividade de avaliação, serão anotadas as informações sobre cada aluno, conforme forem respondendo.

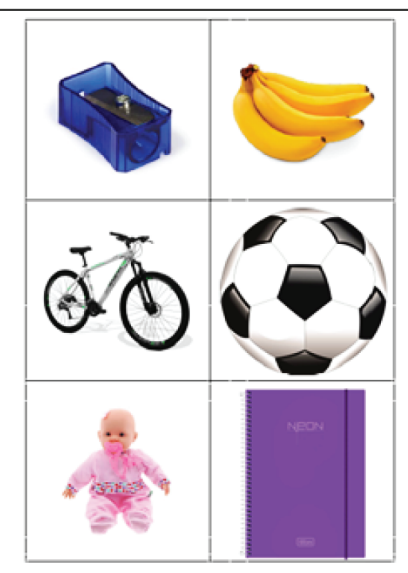

Figura 6 - Excerto de planejamento e instrumento de avaliação de consciência silábica

Fonte: Marian Neves Dante, jogo doado à Didacoteca. Imagens: Google Imagens.

Além dos jogos, as professoras utilizaram, como instrumentos avaliativos, folhas estruturadas produzidas por elas mesmas, objetivando uma tarefa de sistematização, o que proporciona um registro de avaliação mais individualizado das habilidades de consciência silábica demandadas pelos jogos. Essa diversificação dos instrumentos contribui para uma multiplicação das informações sobre as aprendizagens das crianças que, sem dúvida, poderá auxiliar a professora nas suas escolhas didáticas, de modo a favorecer o avanço do grupo e de cada aluno no processo de alfabetização. A atividade mostrada na Figura 4 foi proposta após a realização do jogo "Batalha das Palavras".

No próximo bloco de análises, focalizamos instrumentos que objetivam avaliar a escrita de palavras e pequenos textos. Ferreiro e Teberosky (1985) definem os níveis de conceitualização da escrita, utilizando números do 1 ao 5 para denominá-los. No exercício docente, entretanto, foi o nome das hipóteses em jogo em cada nível que se popularizou. Assim, classificar as escritas das crianças em níveis pré-silábico, silábico, silábico-alfabético e alfabético tornou-se uma tarefa cotidiana das alfabetizadoras.

O clássico teste psicogenético de escrita, que também se popularizou entre as professoras, propunha a produção de palavras de um mesmo campo semântico, com diferentes números de sílabas, e a escrita de frase, o qual inspirou a testagem apresentada na Figura 7. Morais (2012), porém, levanta um alerta, sendo categórico ao afirmar que, para avaliar a compreensão do sistema de escrita pelos alunos, não há necessidade de circunscrever a seleção de palavras a um determinado contexto ou campo semântico. Os alunos devem conhecer o significado das palavras, mas estas não podem ter sido por eles memorizadas. Mais importante do que o contexto é contemplar, além de palavras com quantidades distintas de sílabas, composições silábicas diferentes das do padrão canônico da língua portuguesa consoante-vogal (CV). 
Na Figura 7, temos o planejamento de uma situação avaliativa realizada coletivamente em turma de primeiro ano, no início do ano letivo, e o instrumento utilizado para tal avaliação.

Realizarei com a turma a testagem de escrita de quatro palavras e uma frase, desenvolvida por Ferreiro (1982), através de uma folha estruturada com imagens. Palavras: cola, caderno, canetinha, giz. Frase: A cola está na mochila. Realizarei o ditado das imagens e da frase oralmente, ditando-as uma por uma e aguardando até todos finalizarem a escrita para seguir para a próxima palavra. Explicarei que é muito importante que cada um escreva como acha que é, sem solicitar auxílio para professora ou colega, para que eu possa ver a escrita de todos e pensar em outras atividades que os ajudem a aprender mais. Em seguida, as crianças poderão pintar os desenhos.

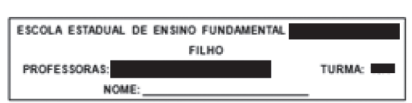

ESCREVA O NOME DOS MATERLAIS:

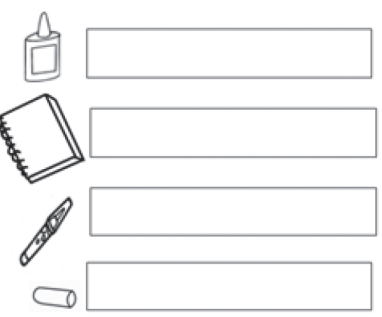

ESCREVAAFRASE DITADA PELAPROFESSORA:

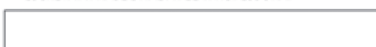

Figura 7 - Excerto de planejamento de testagem avaliativa de escrita e instrumento de registro pelos alunos

Fonte: Mariele Grösz, jogo doado à Didacoteca. Imagens: Google Imagens.

Apesar de a professora ter escolhido palavras de um mesmo campo semântico, o mais importante é que tal seleção considera diferentes estruturas silábicas, tais como: CV, CVC e CCV. Por se tratar de uma turma que estava iniciando o ano letivo, tal instrumento compôs a avaliação diagnóstica com a finalidade de identificar o que seus alunos já sabiam sobre o sistema de escrita, possibilitando a classificação das produções de acordo com os níveis psicogenéticos. Tal classificação não tem um fim em si mesma, ela só é útil ao servir de informação para orientar as estratégias de ensino da professora, tal como está explicitado na descrição da situação avaliativa.

No instrumento de "Autoditado" (Figura 8), utiliza-se palavras de distintos campos semânticos, tendo como preocupação principal as diferentes estruturas das sílabas. De acordo com o planejamento da docente, a escrita deveria ser feita autonomamente pelos alunos. Já o instrumento chamado "Atividade de escrita" (Figura 9) solicita da criança, além da leitura de palavra, a escrita de um pequeno texto, tendo como base as imagens presentes no recurso. Cabe ressaltar o cuidado estético na seleção de imagens reais e o potencial de criação que imagens pouco óbvias podem suscitar na produção escrita. A professora percebeu, durante sua atuação docente, que essas estratégias foram importantes para expandir o repertório de ideias de escrita das crianças (Fagundes, 2019). Ambos os instrumentos de avaliação foram utilizados ao final do ano letivo, quando a turma estava se sentindo um pouco mais segura ante as propostas de produção de pequenos textos. 


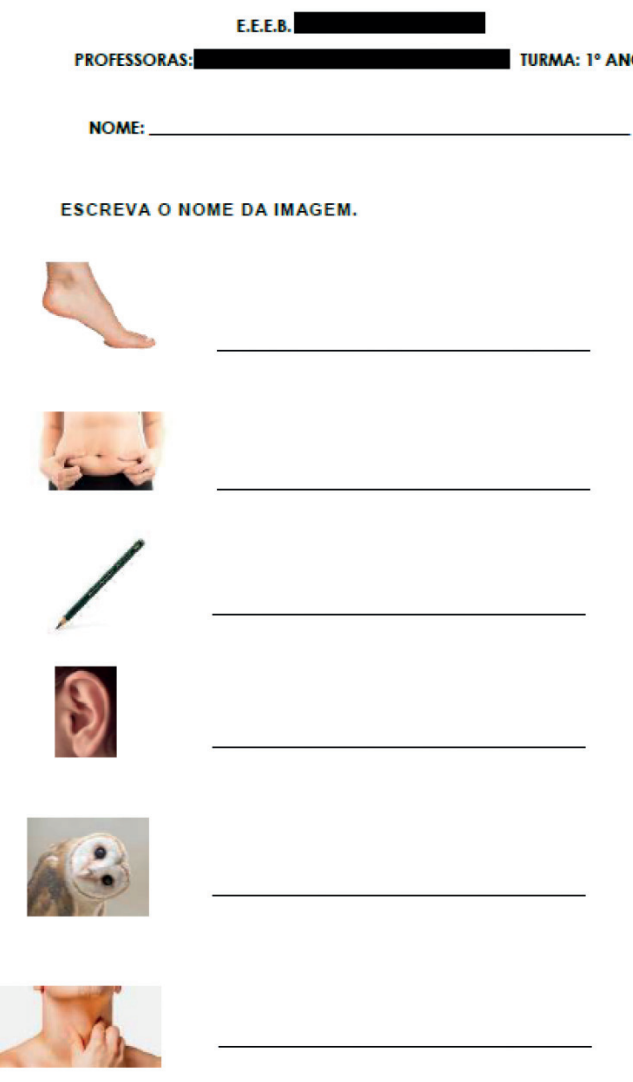

\section{Figura 8 - Excerto de planejamento com descrição do autoditado e instrumento de registro}

Fonte: Francine Fagundes, jogo doado à Didacoteca. Imagens: Google Imagens

Em todos os casos, a professora consegue inferir, por meio da escrita das crianças e do conhecimento teórico sobre as hipóteses formuladas por elas quando em processo de alfabetização, o nível em que cada uma se encontra. O caderno do Pnaic, chamado Avaliação no ciclo de alfabetização: reflexões e sugestões, salienta que

a realização de atividades que envolvem a escrita espontânea de palavras é fundamental, pois por meio dela podemos perceber, por exemplo, se as crianças usam letras, se há variação no repertório de letras, se há correspondência entre as letras e a pauta sonora das palavras, se há marcação de sílabas completas e de diferentes estruturas etc. (Brasil. MEC. SEB, 2012, p. 46).

Mesmo considerando que o nível de escrita é provisório e, muitas vezes, fortemente marcado pela disposição e engajamento da criança no momento da avaliação, ele serve para auxiliar a professora a planejar estratégias de ensino ajustadas ao que cada criança precisa para avançar rumo à compreensão do sistema alfabético-ortográfico de escrita. 


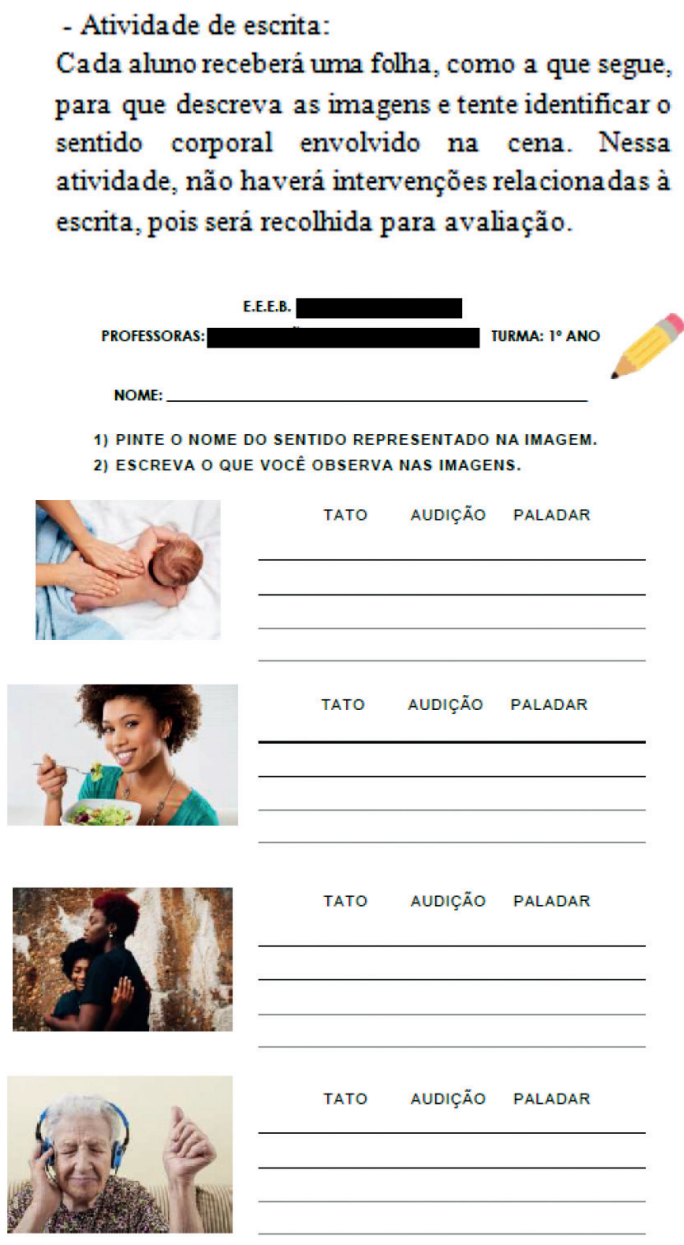

\section{Figura 9 - Excerto de planejamento com descrição de atividade de escrita e instrumento de registro}

Fonte: Francine Fagundes, jogo doado à Didacoteca. Imagens: Google Imagens

A identificação dos níveis psicogenéticos de escrita está vinculada ao que Soares (2016) chamou de "paradigma construtivista". De acordo com a autora, a partir dessa perspectiva, é possível compreender quais as hipóteses que a criança constrói sobre a natureza da escrita, justamente porque o objeto de conhecimento em questão é a escrita em um sentido mais amplo, como um sistema de representação, que passa a ser reconstruído internamente pela criança. Porém, essa não é a única possibilidade de avaliação e de interpretação das escritas infantis nas turmas de alfabetização. Há outra vinculada ao paradigma fonológico (Soares, 2016), no qual se focaliza como a escrita representa os sons da fala, ou seja, como se dá o funcionamento das relações fonema-grafema na ortografia do português brasileiro. O objeto de conhecimento é o sistema de escrita alfabético-ortográfico, tomado como um construto cultural e exterior à criança. A interpretação propiciada pelo paradigma fonológico tende a ser mais útil para as escritas mais avançadas, ou seja, para aquelas em que as crianças já 
demonstram fonetização da escrita, considerando, ainda que de modo inicial, as relações entre o estrato sonoro e sua correspondência gráfica, pois, a partir desse período, passam a coexistir processos cognitivos - paradigma construtivista - e processos linguísticos - paradigma fonológico - nas escritas infantis (Soares, 2016).

No quadro do paradigma fonológico, também é possível avaliar a consciência fonografêmica que, segundo Soares (2016, p. 226 - grifo da autora), é o processo no qual "[...] a criança precisa representar os fonemas da palavra por grafemas", ou seja, ela precisa ser capaz de "[...] produzir relações fonema-grafema na escrita".

Um jogo que também tem auxiliado professoras na avaliação do conhecimento das relações fonema-grafema é o conhecido "jogo da forca", sintetizado a seguir, por meio do qual é possível identificar quais crianças já estabelecem determinadas correspondências que são pertinentes no português brasileiro. Uma proposta que pode ser associada posteriormente a esse jogo consta na atividade da Figura 10, em que se avalia a capacidade da criança na representação de fonemas em grafemas, incentivando a reflexão e a escrita alfabética.

Jogo da forca estruturado: desenho uma imagem no quadro e indico o número de letras da palavra com tracinhos. Questiono as crianças sobre quais letras acham que irão aparecer na palavra, bem como realizo mediações questionando as relações entre sons e letras para compor as sílabas.

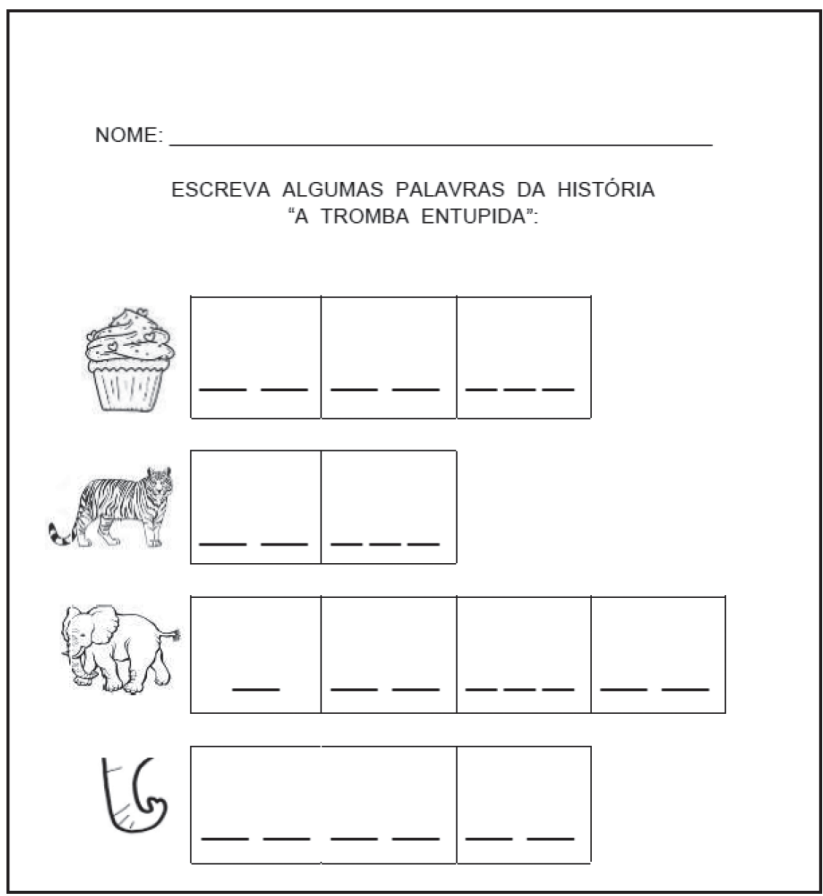

\section{Figura 10 - Excerto de planejamento com descrição do "jogo da forca" e instrumento de registro de atividade avaliativa}

Fonte: Laura Dexheimer Trein, jogo doado à Didacoteca. Imagens: Google Imagens. 
Com esse instrumento, a professora pode mapear quais são as correspondências no nível dos grafemas - assinalados pelos tracejados no interior de cada sílaba, representada pelos retângulos - que a turma já domina e quais ainda precisa avançar. A presença de palavras com diferentes estruturas silábicas - CV (bolinho), CCV (tigre), V (elefante), CVC (elefante), CCVC (tromba) - e com correspondências regulares diretas (Morais, 2019) - cujas letras são comumente trocadas pelas crianças devido às semelhanças na articulação dos fonemas /p/,/b/,/t///d/f/,/v/ em, por exemplo, bolinho, tigre, elefante, tromba - são importantes focos de avaliação das correspondências entre fonemas e grafemas em turmas de alfabetização quando as crianças passam a escrever de forma alfabética.

Além disso, todas essas situações de escrita de palavras poderiam ser chamadas de "escrita inventada" (Soares, 2016), nas quais as crianças materializam seus entendimentos e compreensões sobre a língua. Poderíamos dizer que a escrita inventada é uma forma de visibilizar as hipóteses de escrita das crianças, no quadro do paradigma construtivista, e de representar a cadeia sonora por escrito, no quadro do paradigma fonológico; e essa visibilização é o que permite que a professora avalie a escrita da criança. Assim, a escrita inventada é um modo de "tornar visível a aprendizagem" (Rinaldi, 2014) das crianças em fase de alfabetização.

Enquanto na avaliação da escrita e da consciência fonografêmica a visibilização dos conhecimentos da criança é possível, mesmo que limitada, na avaliação da leitura há desafios, especialmente no contexto coletivo da sala de aula, visto que esse processo impõe algumas dificuldades, mas não impossibilidades, de registro. O automatismo da leitura pode ser inferido pelo tempo e pela quantidade de palavras lidas pelo sujeito, tanto silenciosamente quanto em voz alta, porém, sabemos que no contexto de sala de aula, muitas vezes, se torna difícil realizar uma avaliação de leitura tendo esses dois critérios. Além disso, consideramos que um instrumento de avaliação bem elaborado permite que a professora evidencie estratégias utilizadas pelos estudantes para ler. Os exemplos apresentados na Figura 10 demonstram algumas possibilidades.

O objetivo da professora ao utilizar o instrumento de avaliação exposto na Figura 10 era inferir, a partir da leitura de palavras, se a criança estabelecia relações fonológicas e se reconhecia palavras estáveis. A seleção de palavras para compor o instrumento foi realizada considerando dois critérios: 1) as que já haviam sido exploradas em diversas propostas didáticas sendo, portanto, bastante conhecidas pelas crianças e 2) as que ainda não haviam sido foco de reflexão e análise em sala de aula. Outro ponto fundamental a ser considerado na escolha das palavras que estarão presentes no instrumento de avaliação é que se levem em conta aspectos linguísticos, tais como palavras com a mesma letra inicial ou final, com extensões semelhantes, com o mesmo número de letras, etc. Ou seja, há uma intencionalidade evidente da professora ao selecionar quais palavras deverão ser lidas pelas crianças. É essa escolha que deixa explícitos os conhecimentos linguísticos e cognitivos que a professora tem a respeito da aprendizagem dos seus alunos, e é tal conhecimento que favorecerá uma avaliação mais apurada das habilidades de leitura utilizadas pelas crianças. 


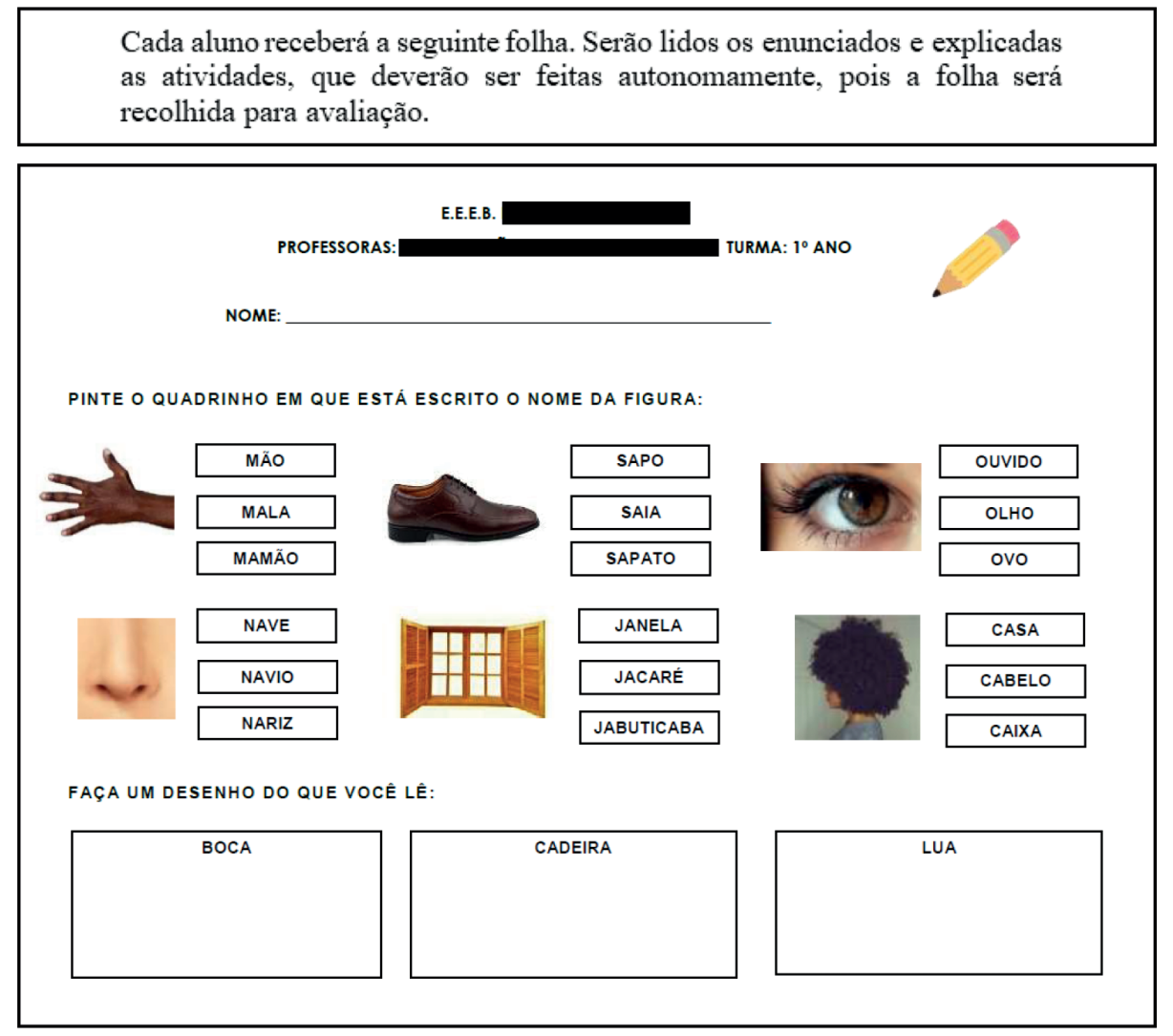

Figura 11 - Excerto de planejamento com descrição de instrumento de avaliação de leitura

Fonte: Francine Fagundes, jogo doado à Didacoteca. Imagens: Google Imagens.

O instrumento de avaliação de leitura da Figura 12 foi planejado para ser utilizado com as crianças que estavam em níveis mais avançados, no mesmo período do ano em que foi empregado o da Figura 11. Em outro texto, discutimos o papel da diferenciação do ensino na alfabetização (Piccoli, 2018); aqui salientamos que, na medida em que a professora adota uma didática que considera os diferentes níveis de aprendizagem de seus alunos, ele também deve realizar avaliações de acordo com esses níveis, pois, dessa maneira, conseguirá aliar uma perspectiva didática que englobe ensino e avaliação e contemple a heterogeneidade da sala de aula.

O objetivo da professora com o instrumento da Figura 12 era a avaliação da leitura autônoma de palavras e frases. Cabe destacar aqui a ordem das orientações dada pela docente na composição do instrumento de avaliação: primeiramente, as crianças deveriam destacar o nome dos animais, solicitando delas, portanto, a leitura de palavras que poderia ser feita por meio de uma estratégia chamada de seleção (Goodman, 1987). Depois, a professora solicita que os alunos liguem as imagens ao trecho escrito que combina com elas. Essa segunda tarefa demanda uma leitura mais avançada, envolvendo uma unidade linguística maior, a frase. Desse modo, conseguimos ver, no mesmo instrumento, a possibilidade de avaliação da progressão das habilidades de leitura em relação tanto à decodificação como à compreensão. 
Para os alunos que já estão em níveis mais avançados de leitura, após a realização da atividade anterior será entregue a seguinte folha, lidos e explorados os enunciados para que seja possivel avaliar a leitura de frases.

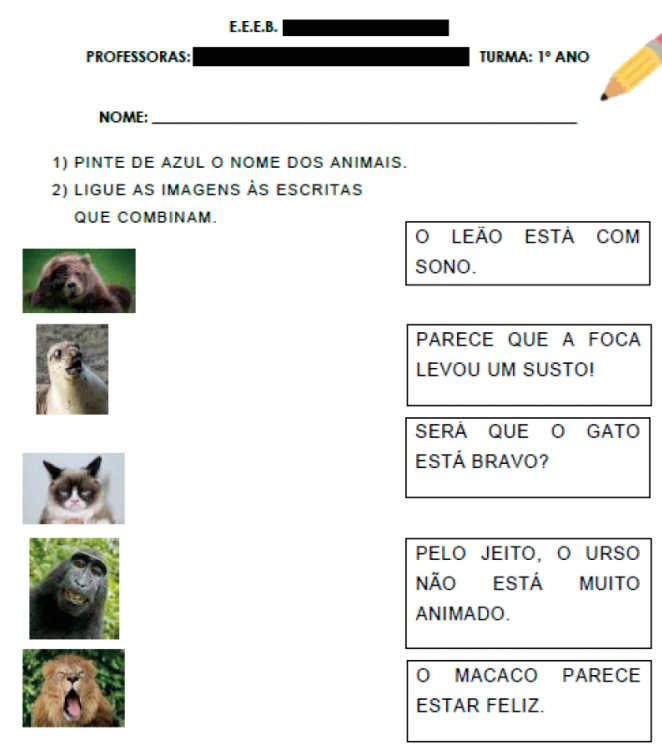

3) ESCREVA COMO O CACHORRO PARECE ESTAR SE SENTINDO

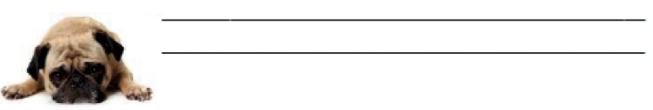

Figura 12 - Excerto de planejamento com descrição de instrumento de avaliação de leitura

Fonte: Fagundes (2019, p. 27).

Outra análise possível desse instrumento se refere ao uso de imagens pouco convencionais - engraçadas, com animais em diferentes expressões faciais -, de frases que possibilitam distintas construções sintáticas e de pontuações variadas. A professora, então, não se utiliza apenas de frases afirmativas e com estrutura convencional: há frases interrogativas, exclamativas e com uso de modalizadores. Tais elementos convergem para a composição de um instrumento de avaliação de leitura que não apenas focaliza a decodificação e a identificação de palavras, mas também busca a produção de sentidos para o que está sendo lido pelas crianças.

Os jogos também são possíveis instrumentos para avaliação da leitura. Vemos, na situação planejada e apresentada na Figura 13, um jogo chamado "Bingo animal", que objetiva avaliar a leitura com foco na consciência grafofonêmica. 


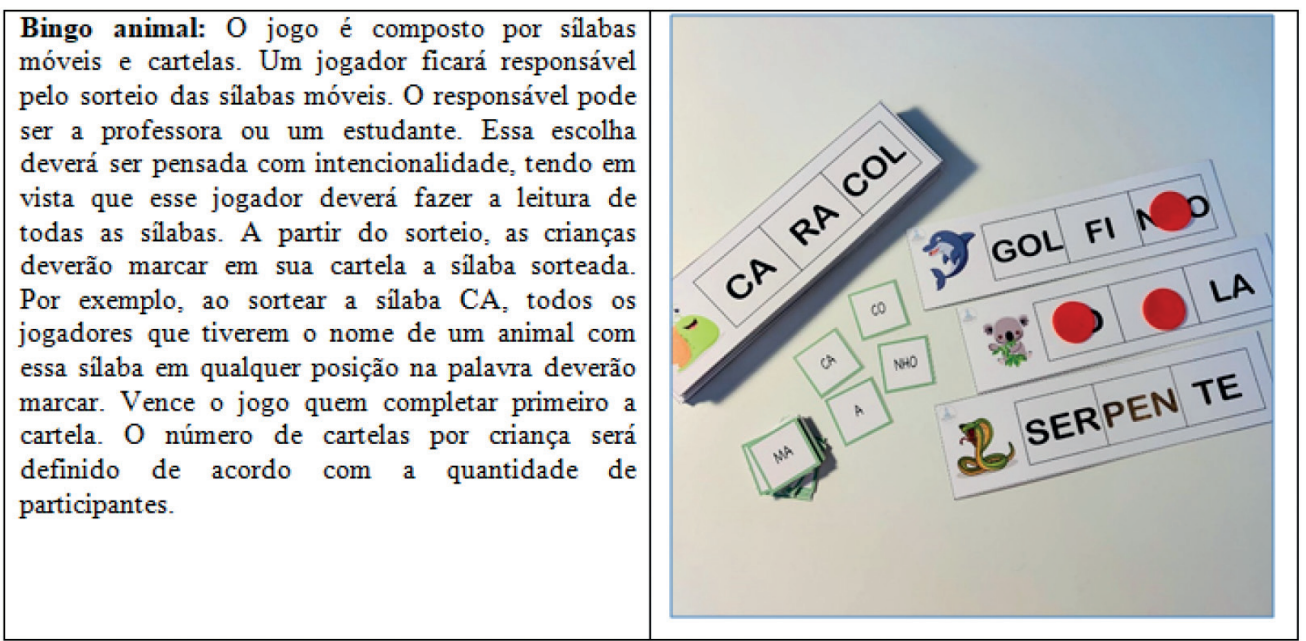

Figura 13 - Descrição e imagem do jogo Bingo animal

Fonte: Laura Bagatini de Almeida e Andressa Borges e Silva. Jogo do Acervo da Illuminare - Ateliê Didático, doado à Didacoteca.

Consciência grafofonêmica, para Soares (2016), é o nível mais avançado da consciência fonológica, alcançado pela associação entre grafemas e fonemas. Segundo a autora, a habilidade de identificação de fonemas é a que mais contribui para a compreensão do princípio alfabético, pois leva "[...] ao reconhecimento de segmentos sublexicais encontrados nas palavras" (Soares, 2016, p. 213). O elemento sublexical focalizado pelo jogo da Figura 13 é a sílaba e solicita do leitor a habilidade de reconhecimento das sílabas escritas e sua posição no interior da palavra. A escolha de palavras com fonemas vocálicos repetidos, nas diferentes sílabas, possibilita que a professora avalie se a criança consegue deslocar sua reflexão para a letra (na escrita) e o fonema (na fala) que acompanha esses fonemas vocálicos, ao selecionar ou não determinada sílaba durante o jogo do bingo. Por exemplo, em uma palavra como CARACOL, a criança em hipótese silábica poderia marcar as duas primeiras sílabas quando a professora ditasse uma que tivesse o fonema vocálico e a letra "A".

\section{Considerações finais}

Com a apresentação e a análise de diferentes instrumentos avaliativos planejados para turmas de primeiro ano do ensino fundamental, mostramos algumas possibilidades para avaliar os conhecimentos envolvidos na aprendizagem inicial da leitura e da escrita, ou seja, a faceta linguística da alfabetização, quais sejam: níveis de conceitualização da escrita, conhecimento das letras, consciência silábica, consciência grafofonêmica e conhecimento das relações fonema-grafema ou consciência fonografêmica e leitura e escrita de palavras. De maneira alguma esses instrumentos aqui apresentados devem ser tomados como "a forma de avaliar a alfabetização". Eles apenas serviram de exemplos para nossa análise e podem inspirar a criação, pelas professoras, dos seus instrumentos avaliativos, destinados às suas turmas de alfabetizandos. 
Nossa pretensão também era apresentar alguns princípios conceituais e metodológicos para auxiliar professoras na tarefa de avaliar seus alunos. Nossa síntese aponta seis princípios que precisam ser considerados na avaliação da alfabetização:

1) a avaliação da aprendizagem dos alunos não está dissociada da perspectiva didática adotada pela professora alfabetizadora;

2) se adotamos uma perspectiva didática que busca considerar a heterogeneidade dos conhecimentos dos alunos, entendemos que a avaliação também deve ser capaz de tornar visível a aprendizagem de cada um dos discentes de uma turma;

3) a avaliação fornece informações para a tomada de decisões no momento de planejar as atividades de ensino;

4) é necessário variar os instrumentos de avaliação para produzir informações diversificadas sobre as aprendizagens dos estudantes;

5) os instrumentos de avaliação e as informações produzidas por eles compõem uma documentação que objetiva tornar visível a aprendizagem;

6) a produção dos instrumentos de avaliação precisa ser criteriosa, em relação tanto à sua forma quanto ao seu conteúdo;

Levando em conta esses princípios, entendemos que o olhar interpretativo da professora, com base nas diferentes teorias que explicam o processo de aprendizagem inicial da leitura e da escrita, é que vai direcionar a avaliação das aprendizagens dos alunos. Essa constatação evidencia a importância do conhecimento específico da professora alfabetizadora para o acompanhamento das aprendizagens das crianças e para a organização de situações de ensino que favoreçam o avanço de seus alunos mediante as diferentes possibilidades de intervenção. Nesse sentido, consideramos que ao menos dois saberes profissionais são essenciais para a avaliação da alfabetização: saberes sobre avaliação e documentação das aprendizagens e saberes sobre os processos de apropriação do conhecimento pela criança, ou seja, conhecimentos linguísticos e cognitivos sobre a aprendizagem inicial da leitura e da escrita.

Por fim, cabe destacar os limites deste texto e das análises aqui realizadas. Primeiramente, salientamos que outros conhecimentos poderiam ser alvo de avaliação pelas professoras, por exemplo, mais habilidades de consciência fonológica, envolvendo consciência silábica, de rimas e aliterações, tão bem exploradas por Morais (2019), mas aqui não foi possível apresentá-las. Além disso, consideramos de extrema relevância uma discussão sobre as formas de registro e acompanhamento das aprendizagens dos alunos, documentadas das mais variadas maneiras, por exemplo, em tabelas, gráficos, quadros, anotações, assim como as formas de registro e comunicação dessas aprendizagens, materializadas em pareceres descritivos, portfólios, fotografias, entre outros, que não puderam ser abordadas e discutidas neste momento, mas que o faremos em breve. 


\section{Referências}

BRANDÃO, A. C. P. A. et al. (Org.). Manual didático: jogos de alfabetização. Brasília: MEC, 2008.

BRASIL. Ministério da Educação (MEC). Secretaria de Educação Básica (SEB). Pacto Nacional pela Alfabetização na Idade Certa: avaliação no ciclo de alfabetização: reflexões e sugestões. Brasília: MEC/SEB, 2012.

FAGUNDES, F. R. Design pedagógico: análise de folhas estruturadas desenvolvidas no contexto da alfabetização. Trabalho de Conclusão de Curso (Licenciatura em Pedagogia) - Faculdade de Educação, Universidade Federal do Rio Grande do Sul, Porto Alegre, 2019.

FERNANDES, C. O.; FREITAS, L. C. Indagações sobre currículo: currículo e avaliação. Brasília: MEC/SEB, 2007.

FERREIRO, E.; TEBEROSKY, A. Psicogênese da língua escrita. Porto Alegre: Artes Médicas, 1985.

GOODMAN, K. S. O processo da leitura: considerações a respeito das línguas e do desenvolvimento. In: FERREIRO, E.; PALACIO, M. G. (Org.). Os processos de leitura e escrita: novas perspectivas. Porto Alegre: Artes Médicas, 1987. p. 11-22.

MORAIS, A. G. Sistema de escrita alfabética. São Paulo: Melhoramentos, 2012.

MORAIS, A. G. Consciência fonológica na educação infantil e no ciclo de alfabetização. Belo Horizonte: Autêntica, 2019.

PERRENOUD, P. Avaliação: da excelência à regulação das aprendizagens: entre duas lógicas. Porto Alegre: Artmed, 1999.

PICCOLI, L. Diferenciação pedagógica e os direitos de aprendizagem na alfabetização. In: PICCOLI, L. et al. (Org.). Pacto Nacional pela Alfabetização na Idade Certa PNAIC UFRGS: práticas pedagógicas, aprendizagem da matemática e políticas públicas. São Leopoldo: Oikos, 2018. p. 19-42.

RINALDI, C. Documentação e avaliação: qual a relação? In: PROJECT ZERO; REGGIO CHILDREN. Tornando visível a aprendizagem: crianças que aprendem individualmente e em grupo. São Paulo: Phorte, 2014.

SOARES, M. Alfabetização: a questão dos métodos. São Paulo: Contexto, 2016.

ZABALA, A. A prática educativa: como ensinar. Porto Alegre: Artmed, 1998. 
Renata Sperrhake doutora em Educação pela Universidade Federal do Rio Grande do Sul (UFRGS), é docente da Faculdade de Educação dessa universidade, onde atua na área de Formação Pedagógica e Linguagem do Curso de Pedagogia, e integrante do Grupo de Pesquisa sobre Educação e Disciplinamento (GPED).

renata.sperrhake@gmail.com

Luciana Piccoli, doutora em Educação pela Universidade Federal do Rio Grande do Sul (UFRGS), é professora associada do Departamento de Ensino e Currículo dessa universidade e integrante do Grupo Interinstitucional de Pesquisa Alfabetização no Brasil: o Estado do Conhecimento (Abec). Atuou como coordenadora geral do Pnaic no âmbito da UFRGS, na edição de 2016. É autora do livro Práticas pedagógicas em alfabetização: espaço, tempo e corporeidade, o qual foi finalista do Prêmio Jabuti, na categoria Educação, em 2013.

lucipcl@gmail.com

Recebido em 29 de março de 2020

Aprovado em 8 de maio de 2020 